\title{
Cronología de las relaciones económicas entre México y Japón y el entorno internacional, 1888-2000
}

DOI: $10.32870 /$ mycp.v6i18.191

Ana Bertha Cuevas Tello*

Cronología de las relaciones económicas entre México y Japón

\begin{tabular}{|c|c|c|}
\hline \multicolumn{3}{|c|}{ y el entorno internacional, $1888-2000$} \\
\hline Año & México-Japón & Entorno internacional \\
\hline \multirow[t]{5}{*}{1888} & $\begin{array}{l}\text { Firma del Tratado de Amistad, } \\
\text { Comercio y Navegación }\end{array}$ & $\begin{array}{l}\text { Industrialización de Occidente e incremento de } \\
\text { los fluios comerciales }\end{array}$ \\
\hline & $\begin{array}{l}\text { Japón se moderniza y se abre al } \\
\text { exterior bajo la restauración Meiji, 1868- } \\
1912\end{array}$ & $\begin{array}{l}\text { Imposición de tratados desiguales por } \\
\text { Occidente a países como Japón y China }\end{array}$ \\
\hline & $\begin{array}{l}\text { México se moderniza y fomenta el } \\
\text { comercio exterior y la inversión } \\
\text { extraniera bajo el porfiriato }\end{array}$ & \\
\hline & $\begin{array}{l}\text { Japón: México, socio estratégico por } \\
\text { su relación con Estados Unidos; } \\
\text { México: Japón, buena opción de } \\
\text { diversificación del comercio }\end{array}$ & \\
\hline & $\begin{array}{l}\text { México exporta a Japón plata y } \\
\text { algodón }\end{array}$ & \\
\hline \multirow[t]{2}{*}{1930} & $\begin{array}{l}\text { México exporta a Japón: algodón, } \\
\text { petróleo, zinc, mercurio, fibras textiles, } \\
\text { plomo, camarones y productos } \\
\text { pesqueros }\end{array}$ & $\begin{array}{l}\text { La gran depresión económica de los años } \\
\text { treinta }\end{array}$ \\
\hline & $\begin{array}{l}\text { Japón se desarrolla como potencia } \\
\text { económica y militar e inicia la } \\
\text { exportación de productos industriales } \\
\text { ligeros al resto del mundo }\end{array}$ & \\
\hline 1938 & $\begin{array}{l}\text { El gobierno mexicano implanta el } \\
\text { modelo económico de sustitución de } \\
\text { importaciones }\end{array}$ & \\
\hline \multirow[t]{4}{*}{$1945-1950$} & $\begin{array}{l}\text { Devastanción y pérdidas económicas } \\
\text { en Japón }\end{array}$ & Fin de la segunda guerra mundial \\
\hline & $\begin{array}{l}\text { En México se activó la economía como } \\
\text { consecuencia de la inestabilidad de la } \\
\text { industria americana durante la guerra }\end{array}$ & $\begin{array}{l}\text { Creación de organismos internacionales, como } \\
\text { el Fondo Monetario Internacional (FMI) y el } \\
\text { Acuerdo General sobre Aranceles y Comercio } \\
\text { (GATT) }\end{array}$ \\
\hline & $\begin{array}{l}\text { Japón se beneficia al dejar en manos } \\
\text { estadounidenses su seguridad } \\
\text { nacional, lo que le permitió invertir ese } \\
\text { capital en la reconstrucción e } \\
\text { industrialización de su país }\end{array}$ & $\begin{array}{l}\text { Creación del Sistema Bretton Woods; se } \\
\text { estableció un tipo de cambio fijo y la } \\
\text { convertibilidad de la moneda para las } \\
\text { transacciones en cuenta corriente }\end{array}$ \\
\hline & $\begin{array}{l}\text { México se convierte en el principal } \\
\text { exportador de materias primas a Japón }\end{array}$ & $\begin{array}{l}\text { Este conjunto de sucesos provocaron un } \\
\text { creciente desarrollo del comercio internacional y } \\
\text { generaron una interdependencia mundial sin } \\
\text { precedentes, lo que le permitió a Estados } \\
\text { Unidos convertirse en el motor del crecimiento } \\
\text { económico mundial }\end{array}$ \\
\hline
\end{tabular}

* Estudiante de la Maestría en Ciencias Sociales, económico mundial 
Cronología de las relaciones económicas entre México y Japón y el entorno internacional, 1888-2000

\begin{tabular}{lll}
\hline Año & \multicolumn{1}{c}{ México-Japón } & Entorno internacional \\
\hline 1955 & $\begin{array}{l}\text { En 1955 Japón forma parte activa del } \\
\text { GATT y gradualmente inicia la } \\
\text { liberalización de sus importaciones }\end{array}$
\end{tabular}

1960-1970 Japón presentó una tasa de crecimiento económico sin precedente, la industria exportadora adquiría mayor fortaleza y ganaba un lugar importante en el mercado internacional gracias a sus avances tecnológicos

El presidente de México, Adolfo López Mateos, realizó la primera visita de un mandatario mexicano a ese país, en el contexto de la diversificación tanto de los flujos comerciales como de los préstamos económicos

Japón inició un proceso de internacionalización. Pudo penetrar en un mayor número de mercados internaciones por medio de la inversión extraniera directa

Surgieron nuevos tipos de relación entre ambos países. Japón le otorgó préstamos oficiales a México y hubo vínculos por inversiones

Se establecen las primeras corporaciones japonesas en México

Durante los sesenta hubo tres cambios importantes en el comercio internacional: 1) la participación de Japón en el comercio internacional aumentó sustancialmente; 2) La composición de las exportaciones japonesas cambiaron de productos intensivos en mano de obra no calificada hacia productos de ingeniería industrial, como acero, maquinaria y automóviles. En la importaciones disminuyó el material crudo para textiles y aumentó el combustible, y 3) la balanza de pagos se volvió positiva

En México, de 1964 a 1970, el PIB creció en promedio 6.8 por ciento

De 1963 a 1972 Japón eliminó, de forma gradual, las tarifas a la importación
Como resultado de la Ronda Kennedy (KR 1964 67) hubo, sin precedentes, una disminución de tarifas comerciales en los países miembros del GATT

Favorable ambiente internacional para el comercio
Crisis en el sistema monetario internacional por la excesiva emisión monetaria por parte de Estados Unidos, lo que provocó altas tasas de inflación en su economía. Estas fuerzas inflacionarias se extendían de un país a otro hasta afectar la economía mundial 
Cronología de las relaciones económicas entre México y Japón y el entorno internacional, $1888-2000$

\begin{tabular}{|c|c|c|}
\hline Año & México-Japón & Entorno internacional \\
\hline \multicolumn{3}{|l|}{$\overline{1973}$} \\
\hline & & $\begin{array}{l}\text { Fin del Sistema Bretton Woods e inicio del tipo } \\
\text { de cambio flexible, lo que provocó desajustes } \\
\text { en el comercio y en los mercados financieros } \\
\text { nacionales e internacionales }\end{array}$ \\
\hline
\end{tabular}

Los inesperados hechos internacionales afectaron de manera grave la economía japonesa, la cual tenía una gran dependencia del petróleo como fuente de energía
Primera crisis del petróleo, la cual provocó una prolongada recesión mundial y la más severa inflación del período de posguerra
Japón toma medidas para sacar a la nación de la crisis. Este país es uno de los primeros en salir de la recesión

Japón traslada al exterior la industria con mayor consumo de combustible

1979-1980 Durante este periodo, el porcentaje de Japón en la producción industrial mundial y en el comercio internacional aumentó en forma considerable

Las fricciones comerciales de Japón con Estados Unidos y la Comunidad Europea se volvió un serio tema de política económica en Japón

Japón tiende hacia el libre comercio después de la Ronda de Tokio. La reducción de cuotas y tarifas fueron mucho mayores que las de muchos países industrializados

México vive la inflación mundial junto con la crisis petrolera, pero los descubrimiento de yacimientos petroleros en el país aliviaron la presión

México utiliza el petróleo como instrumento de negociación y atracción de IED

Los yacimientos petroleros marcaron un nuevo rumbo en las relaciones económicas entre México y Japón

Aumenta el número de compañías japonesas en el país

México implementa una serie de medidas para ampliar el número de socios comerciales y sus fuentes de financiamiento. Sin embargo, los intercambios comerciales con Japón no aumentaron de manera significativa; para Japón, Brasil le resultaba más atractivo
Segunda crisis del petróleo; la economía mundial cae en una prologada recesión
Reconocimiento mundial a Japón como potencia económica

Estados Unidos y los países de Europa continuaban quejándose de lo cerrado del mercado doméstico japonés, especialmente en relación con las barreras no arancelarias 
Cronología de las relaciones económicas entre México y Japón y el entorno internacional, $1888-2000$

\begin{tabular}{|c|c|c|}
\hline Año & México-Japón & Entorno internacional \\
\hline 1981 & $\begin{array}{l}\text { El gobierno mexicano no supo } \\
\text { responder a las circunstancias } \\
\text { económicas que se le presentaron }\end{array}$ & $\begin{array}{l}\text { El precio mundial del petróleo empezó a } \\
\text { descender }\end{array}$ \\
\hline \multirow[t]{3}{*}{1982} & $\begin{array}{l}\text { La crisis económica en México fue } \\
\text { inevitable }\end{array}$ & $\begin{array}{l}\text { Crisis económica en América Latina, Inglaterra y } \\
\text { Estados Unidos }\end{array}$ \\
\hline & $\begin{array}{l}\text { México solicitó préstamos a Japón } \\
\text { para solventar la crisis, los cuales } \\
\text { representaron } 16.9 \text { por ciento del total } \\
\text { de su deuda externa }\end{array}$ & $\begin{array}{l}\text { Estados Unidos estaba desencantado de } \\
\text { ejercer el liderazgo económico, ya que percibía } \\
\text { que sus socios comerciales ejercían políticas y } \\
\text { prácticas tramposas }\end{array}$ \\
\hline & $\begin{array}{l}\text { La crisis provocó reducción de los } \\
\text { vínculos comerciales y de inversión } \\
\text { entre México y Japón }\end{array}$ & \\
\hline 1983 & $\begin{array}{l}\text { México inicia el proceso de apertura } \\
\text { externa cuando sustituye el sistema de } \\
\text { permisos previos por aranceles }\end{array}$ & $\begin{array}{l}\text { La tesorería estadounidense se enfocó a } \\
\text { presionar a otros países para que liberaran sus } \\
\text { mercados de capitales }\end{array}$ \\
\hline \multirow[t]{2}{*}{1985} & $\begin{array}{l}\text { El Acuerdo Plaza obliga al gobierno } \\
\text { japonés a modificar el tipo de cambio. } \\
\text { Como resultado, la economía japonesa } \\
\text { experimentó una recesión a causa del } \\
\text { ajuste que trajo consigo la revaluación } \\
\text { del tipo de cambio }\end{array}$ & $\begin{array}{l}\text { Una de la medidas implementadas por Estados } \\
\text { Unidos para salir de la crisis fue el Acuerdo } \\
\text { Plaza, así como forzar a los países } \\
\text { subdesarrollados a que comerciaran con él y a } \\
\text { que abrieran sus mercados bajo la amenaza de } \\
\text { suspender relaciones comerciales }\end{array}$ \\
\hline & $\begin{array}{l}\text { Mayor exportación de barriles de } \\
\text { petróleo a Japón }\end{array}$ & \\
\hline \multirow[t]{5}{*}{1986} & Recuperación de la economía & \\
\hline & $\begin{array}{l}\text { México se integró como miembro del } \\
\text { GATT e inició la liberalización } \\
\text { económica y la apertura comercial, } \\
\text { convirtiéndose en eje de la política } \\
\text { económica del país }\end{array}$ & \\
\hline & $\begin{array}{l}\text { La economía japonesa presentó un } \\
\text { crecimiento constante hasta comienzo } \\
\text { de los noventa }\end{array}$ & \\
\hline & $\begin{array}{l}\text { Aumentan los intercambios } \\
\text { comerciales y de inversión entre Japón } \\
\text { y México }\end{array}$ & \\
\hline & $\begin{array}{l}\text { Las exportaciones petroleras de } \\
\text { México a Japón quedaron en segundo } \\
\text { plano, lo que dio paso a las } \\
\text { exportaciones manufactureras }\end{array}$ & \\
\hline \multirow[t]{2}{*}{1989} & $\begin{array}{l}\text { Cambio estructural en el sector } \\
\text { productivo mexicano al modernizar y } \\
\text { hacer más eficiente la industria y las } \\
\text { telecomunicaciones }\end{array}$ & $\begin{array}{l}\text { Fin de la guerra fría. Se crea el Foro de } \\
\text { Cooperación Económica de Asia Pacífico } \\
\text { (APEC), con un encuentro inaugural en } \\
\text { Australia }\end{array}$ \\
\hline & $\begin{array}{l}\text { Japón es uno de los países fundadores } \\
\text { del APEC }\end{array}$ & $\begin{array}{l}\text { Las relaciones internacionales son, por vez } \\
\text { primera, auténticamente globales. Las } \\
\text { comunicaciones son instantáneas; la economía } \\
\text { mundial opera de manera simultánea en todos } \\
\text { los continentes y crece la interdependencia } \\
\text { económica }\end{array}$ \\
\hline
\end{tabular}

Se incrementan de manera notable los intercambios comerciales entre México y Japón 
Cronología de las relaciones económicas entre México y Japón y el entorno internacional, 1888-2000

\begin{tabular}{|c|c|c|}
\hline Año & México-Japón & Entorno internacional \\
\hline \multirow[t]{2}{*}{1990} & $\begin{array}{l}\text { El presidente de México, Carlos } \\
\text { Salinas de Gortari, propone al gobierno } \\
\text { de Estados Unidos negociar un tratado } \\
\text { de libre comercio }\end{array}$ & $\begin{array}{l}\text { Reacomodo de la nueva agenda internacional. } \\
\text { El poderío económico supera en importancia al } \\
\text { poderío militar }\end{array}$ \\
\hline & & $\begin{array}{l}\text { Segundo encuentro ministerial del APEC, en } \\
\text { Singapur }\end{array}$ \\
\hline \multirow[t]{3}{*}{1991} & $\begin{array}{l}\text { En la primera mitad de } 1991 \text {, la } \\
\text { economía japonesa entró en una fase } \\
\text { de estancamiento (estallido de la } \\
\text { economía burbuja) }\end{array}$ & $\begin{array}{l}\text { Los principales países industrializados } \\
\text { presionaban a Japón para ejercer un liderazgo } \\
\text { internacional acorde con su poderío económico }\end{array}$ \\
\hline & $\begin{array}{l}\text { En Japón, los productos de alta } \\
\text { tecnología ocupan el primer lugar en } \\
\text { las exportaciones }\end{array}$ & Tercer encuentro ministerial del APEC en Seúl \\
\hline & $\begin{array}{l}\text { De 1991-1994 Japón se encuentra en } \\
\text { un periodo de recesión que mejora } \\
\text { relativamente en } 1994\end{array}$ & Formación de regionalismos \\
\hline \multirow[t]{2}{*}{1992} & $\begin{array}{l}\text { México firma un Tratado de Libre } \\
\text { Comercio con Chile }\end{array}$ & $\begin{array}{l}\text { Adaptabilidad mundial a la megacompetecia } \\
\text { económica }\end{array}$ \\
\hline & $\begin{array}{l}\text { Cambio en proporción y volúmen de } \\
\text { las importaciones japonesas } \\
\text { procedentes de México }\end{array}$ & $\begin{array}{l}\text { Cuarto encuentro ministerial de APEC en } \\
\text { Bangkok }\end{array}$ \\
\hline 1993 & México es miembro del APEC & $\begin{array}{l}\text { Quinto encuentro ministerial de APEC en } \\
\text { Seattle }\end{array}$ \\
\hline \multirow[t]{3}{*}{1994} & $\begin{array}{l}\text { México forma parte de la OCDE, y } \\
\text { entra en vigor el Tratado de Libre } \\
\text { Comercio con América del Norte }\end{array}$ & $\begin{array}{l}\text { Los principales países continúan quejándose del } \\
\text { cerrado mercado japonés }\end{array}$ \\
\hline & $\begin{array}{l}\text { La firma del TLCAN atrajo a México } \\
\text { mayores flujos de IED, ya que fue bien } \\
\text { visto por las trasnacionales como } \\
\text { plataforma para exportar sus productos } \\
\text { a Estados Unidos. Por otro lado, el } \\
\text { comercio se incrementó de manera } \\
\text { notable }\end{array}$ & $\begin{array}{l}\text { Sexto encuentro ministerial del APEC en } \\
\text { Jakarta }\end{array}$ \\
\hline & $\begin{array}{l}\text { México juega un papel importante para } \\
\text { la industria japonesa, ya que facilita el } \\
\text { acceso al mercado estadounidense }\end{array}$ & \\
\hline \multirow[t]{3}{*}{1995} & $\begin{array}{l}\text { A finales de } 1994 \text { la devaluación del } \\
\text { peso mexicano terminó en una grave } \\
\text { crisis económica. Los acontecimientos } \\
\text { sociales ocurridos en en país, como el } \\
\text { levantamiento en armas del EZLN y el } \\
\text { asesinato de dos importantes políticos } \\
\text { mexicanos, ahuyentaron la IED y } \\
\text { disminuyeron los flujos comerciales }\end{array}$ & $\begin{array}{l}\text { El gobierno de Bill Clinton ayudó a México } \\
\text { restablecer la economía por medio de algunos } \\
\text { préstamos económicos }\end{array}$ \\
\hline & $\begin{array}{l}\text { México firma un Tratado de Libre } \\
\text { Comercio con Colombia, Venezuela, } \\
\text { Bolivia y Costa Rica }\end{array}$ & $\begin{array}{l}\text { Séptimo encuentro ministerial del APEC en } \\
\text { Osaka }\end{array}$ \\
\hline & $\begin{array}{l}\text { Creciente participación de los } \\
\text { productos mexicanos en el mercado de } \\
\text { alimentos frescos de Japón }\end{array}$ & \\
\hline
\end{tabular}


Cronología de las relaciones económicas entre México y Japón y el entorno internacional, 1888-2000

\begin{tabular}{|c|c|c|}
\hline \multicolumn{3}{|c|}{ y el entorno internacional, $1888-2000$} \\
\hline Año & México-Japón & Entorno internacional \\
\hline \multirow[t]{2}{*}{1997} & Japón presenta crecimiento negativo & Crisis asiática \\
\hline & & $\begin{array}{l}\text { Noveno encuentro ministerial del APEC en } \\
\text { Vancouver }\end{array}$ \\
\hline 1998 & $\begin{array}{l}\text { Lenta recuperación del crecimiento } \\
\text { económico japonés }\end{array}$ & $\begin{array}{l}\text { Décimo encuentro ministerial del APEC en } \\
\text { Kuala Lumpur }\end{array}$ \\
\hline \multirow[t]{3}{*}{1999} & $\begin{array}{l}\text { Se estudia la posibilidad de firmar un } \\
\text { TLC entre México y Japón }\end{array}$ & \\
\hline & Japón registra un lento crecimiento & $\begin{array}{l}\text { La producción económica mundial cobró } \\
\text { impulso y el crecimiento internacional } \\
\text { experimentó una notable aceleración }\end{array}$ \\
\hline & $\begin{array}{l}\text { Año en que se registró el mayor flujo } \\
\text { de IED japonesa en Méxicc }\end{array}$ & $\begin{array}{l}\text { Décimo primer encuentro ministerial del APEC } \\
\text { en Auckland, Nueva Zelanda }\end{array}$ \\
\hline 2000 & $\begin{array}{l}\text { México firma TLC con Israel y con la } \\
\text { Unión Europea }\end{array}$ & $\begin{array}{l}\text { Décimo segundo encuentro ministerial de APEC } \\
\text { en Brunei Darussalam }\end{array}$ \\
\hline
\end{tabular}

\section{Bibliografía}

Anda, Cuauhtémoc (1999) México y su desarrollo socioeconómico (de Porfirio Díaz a Ernesto Zedillo). Editorial Limusa, México, D.F.

Appleyard, Dennis; Field, Alfred (1998) International Economics. Third editions, Irwin McGraw-Hill.

Banco Nacional de México. Fortalecimiento de la relación económica México-Japón. Conserjería Comercial en Japón. Bizberd, Ilán, José Gurría y Omar Martínez (1998) México ante el fin de la guerra fría. El Colegio de México, México. Falck, Melba. Asia Pacífico en la posguerra espacios de interacción económica y política. Universidad Nacional Autónoma de México.

Gilpin, Robert (1990) The Political Economy of International Relations._Princeton University Press, United States.

Higashi, Chikara y Peter Lauter (1991) The Internationalization of the Japanese Economy. Second Edition, Klumer Academic Publishers, Boston/ Dordrecht/ London.

Hook, Glenn et al. (2001) Japan's International Relations. Routledge Series.

Iver, Neuman; Ole Waever (1997) The Future of International Relations Master in the Making? The New International Relations Series Edited London.

Junji, Banno (1997) "The Political Economy of Japanese Society", Vol. 1, Oxford University Press, United States. Komiya, Ryutaro (1990) The Japanese Economy: Trade, Industry, and Government._University of Tokyo Press.

Lustig, Nora (1994) México hacia la reconstrucción de una economía. El Colegio de México, Fondo de Cultura Económica, México.

Olliqui, José Juan. Temas selectos de la banca y política exterior mexicana (1980-1990). Universidad de Guadalajara.

Nakamura, Takafusa y Bernard Grace (1985) El desarrollo económico del Japón moderno. Ministerio de Relaciones Exteriores, Japón.

Paur, Erich (1999) Japan's War Economy. Routledge Studies in the Growth Economies of Asia, London and New York.

Ramírez, Juan José (coord.) (2001) Asia del Pacífico y los acuerdos bilaterales de libre comercio. El Colegio de México, Centro de Estudios de Asia y África, programa de estudios del APEC.

Jervis, Robert (1996) International Politics, Enduring Concept and Contemporary Issues. Harper Collins Publisher, New York.

Solís, Leopoldo. Políticas comerciales internacionales. El Colegio de México, D.F.

The Nikklei Weekly (2001) Industry anxious for free-trade pacts. Japan.

Uscanga, Carlos (coord.) (2000) Los nuevos desafíos de la política exterior de México en los escenarios regionales. Institución Paradigma de Actividades Científico Culturales, S.C. México. 